\title{
In vitro fermentation of commercial $\alpha$-gluco-oligosaccharide by faecal microbiota from lean and obese human subjects
}

\author{
Shahrul R. Sarbini ${ }^{1}$, Sofia Kolida ${ }^{2}$, Glenn R. Gibson ${ }^{2}$ and Robert A. Rastall ${ }^{2 *}$ \\ ${ }^{1}$ Department of Crop Science, Faculty of Agriculture and Food Science, Universiti Putra Malaysia, Jalan Nyabau, 97008 \\ Bintulu, Sarawak, Malaysia \\ ${ }^{2}$ Department of Food and Nutritional Sciences, University of Reading, Whiteknights, PO Box 226, Reading RG6 6AP, UK \\ (Submitted 15 February 2012 - Final revision received 17 July 2012 - Accepted 23 July 2012 - First published online 2 November 2012)
}

\begin{abstract}
The fermentation selectivity of a commercial source of $\alpha$-gluco-oligosaccharides (BioEcolians; Solabia) was investigated in vitro. Fermentation by faecal bacteria from four lean and four obese healthy adults was determined in anaerobic, pH-controlled faecal batch cultures. Inulin was used as a positive prebiotic control. Samples were obtained at 0, 10, 24 and $36 \mathrm{~h}$ for bacterial enumeration by fluorescent in situ hybridisation and SCFA analyses. Gas production during fermentation was investigated in non-pH-controlled batch cultures. $\alpha$-Gluco-oligosaccharides significantly increased the Bifidobacterium sp. population compared with the control. Other bacterial groups enumerated were unaffected with the exception of an increase in the Bacteroides-Prevotella group and a decrease in Faecalibacterium prausnitzii on both $\alpha$-gluco-oligosaccharides and inulin compared with baseline. An increase in acetate and propionate was seen on both substrates. The fermentation of $\alpha$-gluco-oligosaccharides produced less total gas at a more gradual rate of production than inulin. Generally, substrates fermented with the obese microbiota produced similar results to the lean fermentation regarding bacteriology and metabolic activity. No significant difference at baseline $(0 \mathrm{~h})$ was detected between the lean and obese individuals in any of the faecal bacterial groups studied.
\end{abstract}

Key words: Gluco-oligosaccharides: Prebiotics: Obese subjects

It is now well established that the composition of the colonic microbiota can be modified by the introduction of prebiotics to improve or maintain host health ${ }^{(1)}$. The efficacy of a prebiotic can be evaluated by in vitro batch-culture fermentation systems which have been compared and validated against human and animal in vivo data ${ }^{(2)}$. Batch-culture fermentation systems provide a simple, rapid and inexpensive method of evaluating the prebiotic potential of carbohydrates.

To date, the majority of studies on prebiotics have focused on inulin, fructo-oligosaccharides and galacto-oligosaccharides due to their selective fermentation by bifidobacteria and history of safe commercial use. Nevertheless, there are potential prebiotic oligosaccharides still under investigation, such as $\alpha$-gluco-oligosaccharides. These gluco-oligosaccharides are selectively metabolised by Bifidobacterium, Lactobacillus and Bacteroides but are poorly metabolised by potentially pathogenic bacteria such as enterobacteria and Clostridium ${ }^{\text {(3). }}$. Even though they exhibit promising characteristics, the evidence is not sufficient to classify them as prebiotics presently ${ }^{(4)}$. All studies to date have been carried out by culture-dependent methods, which are not reliable for the analysis of complex bacterial samples. Therefore, further investigation using culture-independent (DNA-based) methods is needed to verify these initial findings.

The human gut microbiota is dominated by two major phyla, the Bacteroidetes and Firmicutes ${ }^{(5)}$. A study has observed that genetically obese mice had a higher proportion of Firmicutes relative to Bacteroidetes compared with lean mice $^{(6)}$. It is also thought that the gut microbiota of obese mice may be more efficient at salvaging energy from the diet than the microbiota of lean mice ${ }^{(7,8)}$. A further in vivo human study has suggested that obese individuals had a higher Firmicutes:Bacteroidetes ratio compared with lean ones $^{(9)}$. However, all the above-mentioned studies only determined changes in Bacteroidetes and Firmicutes, each containing various genera that have diverse metabolic capabilities. Identifying changes at the phylum rather than the genus level could be misleading. Some recent studies have failed to observe differences in Bacteroidetes between lean and obese individuals ${ }^{(10,11)}$. Therefore, the role of the gut

Abbreviations: DP, degree of polymerisation; OA, organic acid.

* Corresponding author: Professor R. A. Rastall, fax +44 118931 0080, email r.a.rastall@reading.ac.uk 
microbiota in obesity remains unclear. Some in vivo animal studies have demonstrated that the composition of the diet, not the obese state, resulted in changes of the gut microbiota $^{(12,13)}$. This raises the possibility of developing prebiotics that influence the microbiota composition and could be consumed as part of a weight management diet.

The aim of the present study is to evaluate the fermentation selectivity of a commercial preparation of $\alpha$-gluco-oligosaccharides (BioEcolians ${ }^{(14)}$ ) by the human faecal microbiota and to assess its prebiotic potential towards lean and obese adults.

\section{Materials and methods \\ Materials}

Unless stated otherwise, all reagents and chemicals used were purchased from Sigma Laboratories. $\alpha$-Gluco-oligosaccharides were provided by Solabia (Pantin). Inulin Frutafit TEX (Sensus) with a degree of polymerisation (DP) $>22$ was used as a positive control.

\section{Faecal inocula}

Faecal samples were obtained from four lean human volunteers (BMI $19-23 \mathrm{~kg} / \mathrm{m}^{2}$; age $30-36$ years) and four obese human volunteers (BMI $35-40 \mathrm{~kg} / \mathrm{m}^{2}$; age $30-36$ years) who were free of known metabolic and gastrointestinal diseases (e.g. diabetes, ulcerative colitis, Crohn's disease, irritable bowel syndrome, peptic ulcers and cancer). The samples were collected on site, kept in an anaerobic cabinet $(10 \%$ $\mathrm{H}_{2}, 10 \% \mathrm{CO}_{2}$ and $80 \% \mathrm{~N}_{2}$ ) and used within a maximum of $15 \mathrm{~min}$ after collection. The samples were diluted 1:10 (w/w) in anaerobic PBS (0.1 mol/l, $\mathrm{pH} 7 \cdot 4)$ and homogenised in a stomacher (Stomacher 400; Seward) for $2 \mathrm{~min}$ at normal speed.

\section{In vitro fermentations}

Sterile stirred batch-culture fermentation systems ( $50 \mathrm{ml}$ working volume) were set up, and aseptically filled with $45 \mathrm{ml}$ sterile, pre-reduced, basal medium (peptone water $2 \mathrm{~g} / \mathrm{l}$ (Oxoid), yeast extract $2 \mathrm{~g} / \mathrm{l}$ (Oxoid), $\mathrm{NaCl} 0.1 \mathrm{~g} / \mathrm{l}, \mathrm{K}_{2} \mathrm{HPO}_{4} 0.04 \mathrm{~g} / \mathrm{l}$, $\mathrm{KH}_{2} \mathrm{PO}_{4} 0.04 \mathrm{~g} / \mathrm{l}, \mathrm{MgSO}_{4} \cdot 7 \mathrm{H}_{2} \mathrm{O} 0.01 \mathrm{~g} / \mathrm{l}, \mathrm{CaCl}_{2} \cdot 6 \mathrm{H}_{2} \mathrm{O} 0.01 \mathrm{~g} / \mathrm{l}$,
$\mathrm{NaHCO}_{3} 2 \mathrm{~g} / \mathrm{l}$, Tween-80 $2 \mathrm{ml}$ (BDH), haemin $0.05 \mathrm{~g} /$, vitamin $\mathrm{K}_{1} 10 \mu \mathrm{l}$, cysteine.HCl $0.5 \mathrm{~g} / \mathrm{l}$, bile salts $0.5 \mathrm{~g} / \mathrm{l}, \mathrm{pH}$ $7 \cdot 0)$ and gassed overnight with $\mathrm{O}_{2}$-free $\mathrm{N}_{2} \quad(15 \mathrm{ml} / \mathrm{min})$. The carbohydrate substrates were added to the respective fermentation vessels just before the addition of the faecal slurry. Concentration of the test substrates was $1 \%(\mathrm{w} / \mathrm{v})$ in $50 \mathrm{ml}$ culture fluid $(0.5 \mathrm{~g})$. The temperature was kept at $37^{\circ} \mathrm{C}$ and the $\mathrm{pH}$ was controlled between 6.7 and 6.9 using an automated pH controller (Fermac 260; Electrolab). Each vessel was inoculated with $5 \mathrm{ml}$ of fresh faecal slurry $(1: 10, \mathrm{w} / \mathrm{w})$. The batch cultures were run over a period of $36 \mathrm{~h}$ and $5 \mathrm{ml}$ samples were obtained from each vessel at 0, 10, 24 and $36 \mathrm{~h}$ for fluorescent in situ hybridisation ${ }^{(15)}$ and SCFA analysis. Finally, eight replicate batch culture fermentations were set up, each inoculated with one of eight different human faecal inocula (four lean and four obese).

\section{Bacterial enumeration}

Synthetic oligonucleotide probes targeting specific regions of the $16 \mathrm{~S}$ ribosomal RNA molecule, labelled with the fluorescent dye Cy3, were utilised for the enumeration of bacterial groups: Chis150 ${ }^{(16)}$, Lab158 ${ }^{(17)}$, Erec482 $2^{(16)}$, Prop853 $3^{(18)}$, Fpra655 (19), Rbro730/Rfla729(20), Bac303 ${ }^{(21)}$, Bif164 ${ }^{(22)}$ and Ato291 23 (23) (Table 1). Samples $(375 \mu \mathrm{l})$ obtained from each vessel at each sampling time were fixed for $4 \mathrm{~h}\left(4^{\circ} \mathrm{C}\right)$ in $1125 \mu \mathrm{l}(4 \%$, $\mathrm{w} / \mathrm{v})$ paraformaldehyde. Fixed cells were centrifuged at $13000 \mathrm{~g}$ for $5 \mathrm{~min}$ and washed twice in $1 \mathrm{ml}$ filtered sterilised PBS. The washed cells were resuspended in $150 \mu$ l filtered PBS and stored in $150 \mu \mathrm{l}$ ethanol $(99 \%)$ at $-20^{\circ} \mathrm{C}$ for at least $1 \mathrm{~h}$ before further processing. Samples $(10 \mu \mathrm{l})$ were diluted in a suitable volume of PBS in order to obtain 20-100 fluorescent cells in each field of view and $20 \mu$ l of the above solution were added to each well of a six-well polytetrafluoroethylene/ poly-L-lysine-coated slide (Tekdon, Inc.). The samples were dried for $15 \mathrm{~min}$ in a drying chamber $\left(46^{\circ} \mathrm{C}\right)$. They were then dehydrated, using an alcohol series (50, 80 and $96 \%$ (v/v) ethanol) for $3 \mathrm{~min}$ in each solution. Slides were returned in the drying oven for $2 \mathrm{~min}$ to evaporate excess ethanol before adding the hybridisation mixture. The hybridisation mixture ( $50 \mu \mathrm{l}$ consisting of $5 \mu \mathrm{l}$ probe and $45 \mu \mathrm{l}$ hybridisation buffer) was added to each well and left to hybridise for $4 \mathrm{~h}$ in a microarray hybridisation incubator (Grant-Boekel). After hybridisation,

Table 1. $16 \mathrm{~S}$ ribosomal RNA oligonucleotide probes used in the present study

\begin{tabular}{|c|c|c|}
\hline Probe name & Specificity & Sequence $\left(5^{\prime}-3^{\prime}\right)$ \\
\hline Chis150 & Most of the Clostridium histolyticum group (Clostridium clusters I and II) ${ }^{(16)}$ & TTATGCGGTATTAATCTYCCTTT \\
\hline Lab158 & Lactobacillus-Enterococcus ${ }^{(17)}$ & GGTATTAGCAYCTGTTTCCA \\
\hline Erec482 & $\begin{array}{l}\text { Most of the Clostridium coccoides-Eubacterium rectale group } \\
(\text { Clostridium clusters XIVa and XIVb) }\end{array}$ & GCTTCTTAGTCARGTACCG \\
\hline Prop853 & Clostridium cluster IX $\mathrm{X}^{(18)}$ & ATTGCGTTAACT CCGGC \\
\hline Fpra655 & Faecalibacterium prausnitzii and relatives ${ }^{(19)}$ & CGC CTA CCT CTG CAC TAC \\
\hline Rbro730 & Clostridium sporosphaeroides, Ruminococcus bromii, Clostridium leptum ${ }^{(20)}$ & TAAAGCCCAGYAGGCCGC \\
\hline Rfla729 & Ruminococcus albus, Ruminococcus flavefaciens ${ }^{(20)}$ & AAAGCCCAGTAAGCCGCC \\
\hline Вас303 & Most Bacteroidaceae and Prevotellaceae, some Porphyromonadaceae ${ }^{(21)}$ & CCAATGTGGGGGACCTT \\
\hline Bif164 & Bifidobacterium spp. ${ }^{(22)}$ & CATCCGGCATTACCACCC \\
\hline Ato291 & Atopobium cluster ${ }^{(23)}$ & GGTCGGTCTCTCAACCC \\
\hline
\end{tabular}


slides were washed in $50 \mathrm{ml}$ washing buffer for $15 \mathrm{~min}$. They were then dipped in cold water for a few seconds and dried with compressed air. Thereafter, $5 \mu$ l of polyvinyl alcohol mounting medium with 1,4-diazabicyclo(2,2,2)octane were added onto each well and a cover slip was placed on each slide (20 mm, thickness no. 1; VWR). The slides were examined under an epifluorescence microscope (Eclipse 400; Nikon) using the Fluor 100 lens. For each well, fifteen different fields of view were enumerated.

\section{Organic acid analyses}

Analysis was performed using an ion-exclusion HPLC system (LaChrom Merck Hitachi) equipped with a pump (L-7100), an RI detector (L-7490) and an autosampler (L-7200). Data were collected using Jones Chromatography Limited for Windows 2.0 software. The column used was an ion-exclusion Rezex ROA-Organic Acid H ${ }^{+}(8 \%)(300 \times 7.80 \mathrm{~mm}$; Phenomenex $)$. Guard columns were SecurityGuard ${ }^{\mathrm{TM}}$ Carbo- $\mathrm{H}^{+} 4 \times 3.0 \mathrm{~mm}$ cartridges (Phenomenex). The eluent used was $0.0025 \mathrm{~mm}-\mathrm{H}_{2} \mathrm{SO}_{4}$ in HPLC-grade water.

Samples $(1 \mathrm{ml})$ from each fermentation time point were centrifuged at $13000 \mathrm{~g}$ for $10 \mathrm{~min}$. Supernatants were filtered through a $0.22 \mu \mathrm{m}$ filter unit (Millipore) and $20 \mu \mathrm{l}$ were injected into the HPLC, operating at a flow rate of $0.5 \mathrm{ml} /$ min with a heated column at $84 \cdot 2^{\circ} \mathrm{C}$. The sample run-time was $35 \mathrm{~min}$. Sample quantification was carried out using calibration curves for lactate, acetate, propionate and butyrate at concentrations of $12 \cdot 5,25,50,75$ and $100 \mathrm{~mm}$.

\section{Rate of gas production}

Sterile glass Balch tubes $(18 \times 150 \mathrm{~mm}$; Bellco $)$ containing $13.5 \mathrm{ml}$ pre-reduced basal medium (peptone water $2 \mathrm{~g} / 1$ (Oxoid), yeast extract $2 \mathrm{~g} / \mathrm{l}$ (Oxoid), $\mathrm{NaCl} 0 \cdot 1 \mathrm{~g} / 1, \mathrm{~K}_{2} \mathrm{HPO}_{4}$ $0.04 \mathrm{~g} / \mathrm{l}, \mathrm{KH}_{2} \mathrm{PO}_{4} 0.04 \mathrm{~g} / \mathrm{l}, \mathrm{MgSO}_{4} \cdot 7 \mathrm{H}_{2} \mathrm{O} 0.01 \mathrm{~g} / 1, \mathrm{CaCl}_{2} \cdot 6 \mathrm{H}_{2} \mathrm{O}$ $0.01 \mathrm{~g} / \mathrm{l}, \mathrm{NaHCO}_{3} 2 \mathrm{~g} / \mathrm{l}$, Tween-80 $2 \mathrm{ml}$, haemin $0.05 \mathrm{~g} / \mathrm{l}$, vitamin $\mathrm{K}_{1} 10 \mu \mathrm{l}$, cysteine.HCl $0.5 \mathrm{~g} / \mathrm{l}$, bile salts $0.5 \mathrm{~g} / \mathrm{l}, \mathrm{pH} 7.0$ ) were placed in the anaerobic cabinet and kept overnight. Substrates $(1: 10, \mathrm{w} / \mathrm{v})$ were added to the fermentation tubes just before the addition of the faecal inocula (1:10, $\mathrm{w} / \mathrm{v})$. The tubes were then sealed with a gas-impermeable butyl rubber septum (Bellco) and aluminium crimp (SigmaAldrich). The tubes were incubated at $37^{\circ} \mathrm{C}$ with constant agitation. The volume of gas generated by faecal bacteria from each substrate was measured every $3 \mathrm{~h}$ up to $36 \mathrm{~h}$ fermentation by inserting a sterile needle (BD, 23G X 1 inch) attached to a transducer (Gems Sensors) into the butyl rubber septum of each tube. The pressure build-up in the headspace was measured in pounds per square inch. After each measurement, the headspace of each tube was allowed to equilibrate with the atmosphere. The gas production experiments were performed in four replicates for each substrate. Quantification of gas volume (ml) was carried out using calibration curves of air pressure (pounds per square inch) by injecting known volumes of air into the culture tubes $(0 \cdot 5-7 \mathrm{ml})$.

\section{Statistical analyses}

Statistical analysis was performed using SPSS for Windows (version 16.0; SPSS, Inc.). One-way ANOVA and post boc Tukey's tests were used to determine the significant difference of substrate used on bacterial group population, SCFA production and gas production. Principal component analysis was performed using XLSTAT-Pro software (Addinsoft) in accordance with Pearson's correlation test to identify correlated variables among the target bacterial groups at baseline $(0 \mathrm{~h})$ in the lean and obese faecal microbiota populations. Differences were deemed significant when $P<0.05$.

\section{Results}

\section{Bacterial enumeration}

The average bacterial concentrations of the test substrates fermented by the lean and obese human faecal slurries are shown in Table 2. There was a significant increase in the Bif164 populations in the lean fermentations following the response to $\alpha$-gluco-oligosaccharides at all time points compared with $0 \mathrm{~h}$. Furthermore, the Bif 164 populations at $36 \mathrm{~h}$ fermentation were significantly higher in $\alpha$-gluco-oligosaccharides compared with inulin $(P<0.05)$. Other members of the actinobacteria group, i.e. Ato291, on $\alpha$-gluco-oligosaccharides were significantly lesser in comparison with inulin at $36 \mathrm{~h}$. There were significant increases in the Bac303 group on both $\alpha$-gluco-oligosaccharides and inulin at 24 and $36 \mathrm{~h}$, respectively. A significant decrease in Fpra655 was observed with both test substrates $(P<0.01)$ at all time points. No significant changes were detected in the other bacterial populations. Also, there were no significant changes in the total cell count (enumerated by 4',6-diamidino-2-phenylindole stain) on both substrates of the lean fermentation.

Analyses of the obese faecal microbiota composition at baseline $(0 \mathrm{~h})$ did not reveal any significant differences in the specific bacterial groups between the obese and lean human faecal microbiota. The total cell counts were higher in the obese human faecal samples compared with lean faecal samples $(P<0.05)$. However, a considerably higher percentage of the baseline microbiota was accounted for in the lean cultures compared with the obese cultures by the probe set used. The principal component analysis results for all parameters related to gut bacteria and the distribution of the faecal microbiota from all donors at baseline $(0 \mathrm{~h})$ are shown in Fig. 1. The first and second principal components were responsible for $63 \%$ of the total variance. The projection of the parameters in the plane by these principal components did not separate the lean and obese faecal microbiota and no clustering was observed, indicating no significant differences among the faecal inocula in accordance with Pearson's correlation test $(P>0 \cdot 05)$.

There was a significant increase of Bif164 in response to $\alpha$-gluco-oligosaccharides tested at all time points from $0 \mathrm{~h}$, which was similar to the lean fermentation. Also, the Bif164 populations at $36 \mathrm{~h}$ with $\alpha$-gluco-oligosaccharides were significantly higher compared with inulin fermentation $(P<0.05)$. Generally, substrates fermented with the obese microbiota produced similar results to the lean fermentation, 
Table 2. Bacterial populations ( $\log _{10}$ cells $/ \mathrm{ml}$ batch culture fluid) in pH-controlled batch cultures at $0,10,24$ and $36 \mathrm{~h}$ inoculated with the lean and obese faecal microbiota

(Mean values and standard deviations, $n 4$ )

\begin{tabular}{|c|c|c|c|c|c|c|c|c|c|}
\hline \multirow[b]{3}{*}{ Probe/stain } & \multirow[b]{3}{*}{ Time (h) } & \multicolumn{4}{|c|}{ Lean faecal fermentation } & \multicolumn{4}{|c|}{ Obese faecal fermentation } \\
\hline & & \multicolumn{2}{|c|}{$\begin{array}{c}\alpha \text {-Gluco- } \\
\text { oligosaccharides }\end{array}$} & \multicolumn{2}{|c|}{ Inulin } & \multicolumn{2}{|c|}{$\begin{array}{c}\alpha \text {-Gluco- } \\
\text { oligosaccharides }\end{array}$} & \multicolumn{2}{|c|}{ Inulin } \\
\hline & & Mean & SD & Mean & SD & Mean & SD & Mean & SD \\
\hline \multirow[t]{4}{*}{ Chis150 } & 0 & 7.55 & 0.51 & 7.55 & 0.51 & 7.98 & 0.13 & 7.98 & 0.13 \\
\hline & 10 & 7.49 & 0.33 & 7.64 & 0.38 & 7.89 & 0.29 & $7 \cdot 71$ & 0.18 \\
\hline & 24 & 7.52 & 0.32 & 7.90 & 0.44 & 7.94 & 0.45 & $7 \cdot 62$ & 0.21 \\
\hline & 36 & 7.60 & 0.43 & $7 \cdot 76$ & 0.51 & 7.48 & 0.21 & 7.52 & 0.27 \\
\hline \multirow[t]{4}{*}{ Lab158 } & 0 & $7 \cdot 77$ & 0.31 & $7 \cdot 77$ & 0.31 & $8 \cdot 16$ & 0.28 & $8 \cdot 16$ & 0.28 \\
\hline & 10 & $7 \cdot 74$ & 0.38 & 8.06 & 0.46 & $8.72^{\star}$ & 0.24 & $8 \cdot 76^{*}$ & 0.33 \\
\hline & 24 & 7.50 & 0.09 & $8 \cdot 10$ & 0.63 & $8.69^{b}$ & 0.26 & $8.77^{\mathrm{b} *}$ & 0.36 \\
\hline & 36 & $7.74^{\mathrm{a}}$ & 0.11 & 8.44 & 0.29 & $8.53^{b}$ & 0.20 & 8.54 & 0.45 \\
\hline \multirow[t]{4}{*}{ Erec482 } & 0 & 8.53 & 0.17 & 8.53 & 0.17 & 8.60 & 0.18 & 8.60 & 0.18 \\
\hline & 10 & 8.39 & 0.33 & $8 \cdot 34$ & 0.33 & 8.53 & 0.46 & $8 \cdot 84$ & 0.39 \\
\hline & 24 & $8 \cdot 16$ & 0.39 & $8 \cdot 36$ & 0.30 & 8.62 & 0.47 & 8.55 & 0.39 \\
\hline & 36 & 8.25 & 0.30 & 8.49 & 0.28 & 8.47 & 0.29 & 8.60 & 0.40 \\
\hline \multirow{4}{*}{ Prop853 } & 0 & $8 \cdot 41$ & 0.29 & 8.41 & 0.29 & 8.28 & 0.28 & 8.28 & 0.60 \\
\hline & 10 & 8.26 & 0.30 & 8.45 & 0.17 & $8.68^{b}$ & 0.17 & 8.44 & 0.26 \\
\hline & 24 & 8.46 & 0.48 & 8.52 & 0.16 & 8.33 & 0.38 & 8.26 & 0.27 \\
\hline & 36 & 8.32 & 0.52 & 8.42 & 0.22 & 8.24 & 0.46 & 8.04 & 0.59 \\
\hline \multirow{4}{*}{ Fpra655 } & 0 & 8.58 & 0.34 & 8.58 & 0.34 & 8.57 & 0.10 & 8.57 & 0.34 \\
\hline & 10 & $7 \cdot 81^{\star \star}$ & 0.15 & $7 \cdot 83^{\star *}$ & $0 \cdot 16$ & $8.05^{\star}$ & 0.46 & 8.33 & 0.16 \\
\hline & 24 & $7 \cdot 88^{\star \star}$ & 0.24 & $7.93^{\star \star}$ & 0.19 & $8.06^{\star}$ & 0.32 & $8.05^{\star}$ & 0.19 \\
\hline & 36 & $7 \cdot 70^{\star *}$ & 0.07 & $7 \cdot 80^{\star *}$ & 0.09 & $7 \cdot 73^{\star *}$ & 0.18 & $7 \cdot 72^{\star *}$ & 0.09 \\
\hline \multirow[t]{4}{*}{ Rbro730/Rfla729 } & 0 & 8.36 & 0.44 & $8 \cdot 36$ & 0.44 & 8.67 & 0.54 & 8.67 & 0.44 \\
\hline & 10 & 8.33 & 0.71 & $8 \cdot 17$ & 0.45 & $8 \cdot 21$ & 0.27 & $8 \cdot 26^{\star}$ & 0.45 \\
\hline & 24 & 8.09 & 0.41 & $8 \cdot 33$ & 0.56 & $8 \cdot 18$ & 0.56 & $8 \cdot 32^{*}$ & 0.56 \\
\hline & 36 & 8.07 & 0.27 & 8.22 & 0.45 & $7 \cdot 84^{\star}$ & 0.31 & $8 \cdot 21^{*}$ & 0.45 \\
\hline \multirow[t]{4}{*}{ Вас303 } & 0 & 8.48 & 0.38 & 8.48 & 0.38 & $8 \cdot 61$ & 0.33 & $8 \cdot 61$ & 0.33 \\
\hline & 10 & $9 \cdot 10$ & 0.27 & 9.07 & 0.21 & $9 \cdot 41^{*}$ & 0.11 & $9 \cdot 17^{\star *}$ & 0.36 \\
\hline & 24 & 9.05 & 0.45 & $9 \cdot 27^{\star}$ & 0.28 & $9 \cdot 36^{*}$ & 0.20 & $9 \cdot 05^{\star *}$ & 0.27 \\
\hline & 36 & $9 \cdot 34^{\star}$ & 0.27 & 8.98 & 0.24 & $8 \cdot 86$ & 0.43 & 8.72 & 0.30 \\
\hline \multirow[t]{4}{*}{ Bif164 } & 0 & 8.03 & 0.14 & 8.03 & 0.14 & 7.84 & 0.19 & $7 \cdot 84$ & 0.19 \\
\hline & 10 & $8 \cdot 80^{\star \star}$ & 0.18 & 8.42 & 0.43 & $8 \cdot 90^{\star *}$ & 0.11 & $8.57^{\star *}$ & 0.31 \\
\hline & 24 & $8 \cdot 98^{\star \star}$ & 0.17 & 8.59 & 0.25 & $8 \cdot 75^{\star *}$ & 0.39 & $8 \cdot 50^{\star *}$ & 0.25 \\
\hline & 36 & $8.99^{a * *}$ & 0.27 & $8 \cdot 10$ & 0.47 & $8.91^{\mathrm{a} \star \star}$ & 0.21 & 8.29 & 0.24 \\
\hline \multirow[t]{4}{*}{ Ato291 } & 0 & $8 \cdot 15$ & 0.45 & $8 \cdot 15$ & 0.45 & 7.95 & 0.28 & 7.95 & 0.28 \\
\hline & 10 & 8.35 & 0.20 & 8.47 & 0.66 & $8.50^{\star}$ & 0.09 & 8.60 & 0.36 \\
\hline & 24 & $8 \cdot 31$ & 0.16 & 8.74 & 0.34 & 8.39 & 0.19 & 8.40 & 0.38 \\
\hline & 36 & $8 \cdot 40^{\mathrm{a}}$ & 0.22 & 8.85 & 0.20 & 8.29 & 0.25 & 8.39 & 0.20 \\
\hline \multirow[t]{4}{*}{ DAPI } & 0 & 9.46 & 0.12 & 9.46 & 0.12 & $9 \cdot 74^{b}$ & 0.11 & $9 \cdot 74^{b}$ & 0.11 \\
\hline & 10 & 9.67 & 0.13 & $9 \cdot 70$ & 0.11 & $9 \cdot 81$ & 0.07 & $9 \cdot 86$ & 0.25 \\
\hline & 24 & $9 \cdot 80$ & 0.19 & $9 \cdot 74$ & 0.16 & 9.85 & 0.18 & $9 \cdot 87$ & 0.19 \\
\hline & 36 & 9.87 & 0.21 & 9.69 & 0.22 & 9.84 & 0.26 & 9.85 & 0.23 \\
\hline
\end{tabular}

i.e. increasing Bac303 populations and decreasing Fpra655 populations. However, during the obese slurry fermentation, the populations of Lab158 increased with both substrates, which was not the case in the lean fermentation $(P<0.05)$.

The percentages of the major bacterial phyla in the fermentation using the lean and obese persons' inocula are shown in Table 3, where the total bacterial number of Chis 150 , Lab158, Erec482, Prop853, Fpra655 and Rbro730/Rfla729 represents Firmicutes; Bac303 represents Bacteroidetes; Bif164 and Ato291 represent Actinobacteria. The starting bacterial populations in both lean and obese faecal slurries
$(0 \mathrm{~h})$ demonstrate that Firmicutes was the predominant group followed by Bacteroidetes and then Actinobacteria. No significant difference was detected in all major bacterial phyla $(P>0.05)$ between the lean and obese faecal fermentations.

\section{Organic acid analyses}

Table 4 shows organic acid (OA) concentrations in the lean and obese faecal cultures. Generally, fermentation of the lean faecal microbiota of both substrates produced all OA 


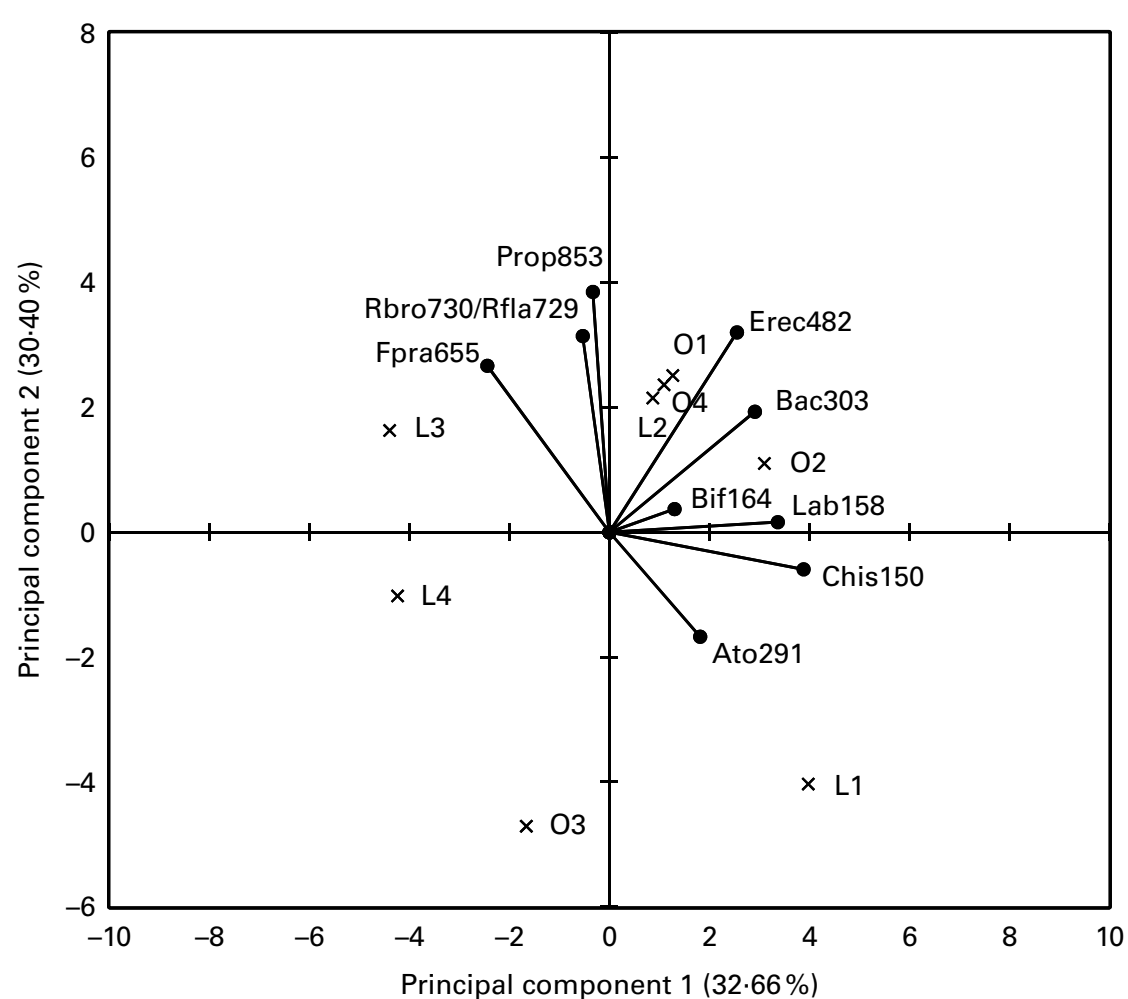

Fig. 1. Principal component analysis score plot of the faecal microbiota groups at baseline $(0 \mathrm{~h})$ for the lean $(\mathrm{L}, n 4)$ and obese $(\mathrm{O}, n 4)$ donors enumerated using fluorescent in situ hybridisation (Chis150, Clostridium histolyticum; Lab158, Lactobacillus/Enterococcus; Erec482, Eubacterium rectale/Clostridium coccoides; Prop853, Clostridium cluster IX; Fpra655, Faecalibacterium prausnitzii; Rbro730/Rfla729, Ruminococcus bromii/Ruminococcus flavefaciens; Bac303, Bacteroides/Prevotella; Bif164, Bifidobacterium spp.; Ato291, Atopobium cluster). The plot shows no clustering, indicating no significant differences between the L and $\mathrm{O}$ donors according to Pearson's correlation test $(P>0.05)$.

except butyrate. Lactate significantly increased early in the $\alpha$-gluco-oligosaccharide fermentation $(10 \mathrm{~h})$ but later diminished. Total OA concentrations significantly increased on both test substrates after $10 \mathrm{~h}$ of fermentation $(P<0 \cdot 01)$. In addition, total OA concentrations with $\alpha$-gluco-oligosaccharides at $36 \mathrm{~h}$ were significantly higher compared with inulin. Acetate was the most prevalent SCFA on both test substrates accounting for $>50 \%$ of the total OA produced followed by propionate and butyrate. Significant increases in acetate were found with both test substrates. The highest acetate concentration was observed following $\alpha$-gluco-oligosaccharide fermentation at $36 \mathrm{~h}$, which was significantly higher than inulin. Significant increases in propionate were found with both substrates, with $\alpha$-gluco-oligosaccharides giving higher propionate levels. There is no significant difference in the acetate:propionate ratio observed in the fermentation of $\alpha$-gluco-oligosaccharide compared with inulin.

Substrates fermented with the obese microbiota exhibited similar OA patterns to the lean fermentation, i.e. a significantly higher total OA concentration with $\alpha$-gluco-oligosaccharides compared with inulin at $36 \mathrm{~h}$. However, for $\alpha$-gluco-oligosaccharides, the acetate:propionate ratio in the obese faecal

Table 3. Percentage of the major bacterial phyla in $\mathrm{pH}$-controlled batch cultures of the lean and obese human faecal fermentations at $0,10,24$ and $36 \mathrm{~h}^{\star}$

\begin{tabular}{|c|c|c|c|c|c|c|c|c|c|}
\hline \multirow[b]{3}{*}{ Substrate } & \multirow[b]{3}{*}{ Time $(\mathrm{h})$} & \multicolumn{8}{|c|}{ Phylum proportion (\%) } \\
\hline & & \multicolumn{2}{|c|}{ Firmicutes } & \multicolumn{2}{|c|}{ Bacteroidetes } & \multicolumn{2}{|c|}{ Actinobacteria } & \multicolumn{2}{|c|}{$\begin{array}{l}\text { Firmicutes/ } \\
\text { Bacteroidetes }\end{array}$} \\
\hline & & Lean & Obese & Lean & Obese & Lean & Obese & Lean & Obese \\
\hline \multirow[t]{4}{*}{$\alpha$-Gluco-oligosaccharides } & 0 & $68 \cdot 4$ & $74 \cdot 8$ & $17 \cdot 7$ & $18 \cdot 2$ & $14 \cdot 0$ & $7 \cdot 0$ & 3.9 & $4 \cdot 1$ \\
\hline & 10 & $32 \cdot 9$ & 31.6 & 41.6 & $47 \cdot 8$ & $25 \cdot 5$ & $20 \cdot 6$ & 0.8 & 0.7 \\
\hline & 24 & $25 \cdot 6$ & $32 \cdot 2$ & $42 \cdot 6$ & $50 \cdot 0$ & $31 \cdot 8$ & $17 \cdot 8$ & $0 \cdot 6$ & 0.6 \\
\hline & 36 & $17 \cdot 3$ & 35.5 & 53.0 & $26 \cdot 8$ & $29 \cdot 7$ & $37 \cdot 7$ & 0.3 & $1 \cdot 3$ \\
\hline \multirow[t]{4}{*}{ Inulin } & 0 & $69 \cdot 8$ & $73 \cdot 6$ & $16 \cdot 2$ & $18 \cdot 3$ & $14 \cdot 1$ & $8 \cdot 1$ & $6 \cdot 4$ & $5 \cdot 3$ \\
\hline & 10 & $36 \cdot 6$ & $46 \cdot 7$ & 38.5 & 34.9 & 24.9 & $18 \cdot 4$ & 0.9 & $2 \cdot 5$ \\
\hline & 24 & 33.9 & $49 \cdot 8$ & $43 \cdot 2$ & $32 \cdot 3$ & $22 \cdot 9$ & $17 \cdot 9$ & 1.0 & 1.9 \\
\hline & 36 & $41 \cdot 3$ & $55 \cdot 6$ & $30 \cdot 1$ & $25 \cdot 2$ & $28 \cdot 6$ & $19 \cdot 2$ & $1 \cdot 6$ & $4 \cdot 7$ \\
\hline
\end{tabular}

* No significant difference was detected in all major bacterial phyla $(P>0.05)$ between the lean and obese faecal fermentations. 
fermentation was significantly lower than that in the lean faecal fermentation.

\section{Gas production}

The total gas production after $36 \mathrm{~h}$ in the lean and obese fermentations is shown in Fig. 2. No significant differences were observed in the total gas produced between the lean and obese fermentations. Fig. 3 shows the gas production patterns in the lean faecal fermentation. Fermentation of $\alpha$-gluco-oligosaccharides produced gas which peaked at $3 \mathrm{~h}$. Meanwhile, fermentation of inulin produced the highest amount of gas at $6 \mathrm{~h}$. $\alpha$-Gluco-oligosaccharides produced a slower rate of gas combined with lower total gas production compared with inulin $(P<0.05)$. This indicates that $\alpha$-gluco-oligosaccharides were fermented more slowly to produce a more gradual build-up of gas compared with inulin. Fig. 4 shows the gas production patterns in the obese faecal fermentation. Fermentation of $\alpha$-gluco-oligosaccharides produced gas which peaked at the same time with inulin at $3 \mathrm{~h}$. However, thereafter, the gas production rate of $\alpha$-glucooligosaccharide was slower than that of inulin. The fermentation of $\alpha$-gluco-oligosaccharides with the obese faecal inocula was significantly faster than that with the lean faecal inocula $(P<0.05)$. However, no significant difference on the gas production rate of inulin was observed between the lean and obese faecal fermentations $(P>0 \cdot 05)$.

\section{Discussion}

This is the first study to evaluate commercial $\alpha$-glucooligosaccharides (BioEcolians) in a mixed human faecal culture system using modern DNA-based microbiological methods. $\alpha$-Gluco-oligosaccharides gave rise to significant increases in Bifidobacterium populations when compared with inulin. This may be related to the difference in the molecular weight of the substrates tested. $\alpha$-Gluco-oligosaccharides used in the present study have a DP of 5-6 $6^{(24)}$. Our current understanding of prebiotic substances is that low-molecular-weight oligosaccharides are more selectively fermented by bifidobacteria and lactobacilli than high-molecular-weight carbohydrates ${ }^{(4)}$. A study has demonstrated that lower-DP oligodextrans produced by controlled enzymatic hydrolysis resulted in higher fermentation selectivity for bifidobacteria, compared with the parent dextran molecule and other oligodextran fractions with a higher average $\mathrm{DP}^{(25)}$, with a DP of 3 giving higher prebiotic activity than a DP of $2^{(26)}$. This may be due to the fact that the low molecular mass means more non-reducing ends per unit mass, which are susceptible to attack by various exo-acting $\alpha$ - and $\beta$-glucosidases produced by colonic bacteria such as Bifidobacterium spp. ${ }^{(27)}$. Little is known about the biochemical characteristics of $\alpha$-glucosidase enzymes from bifidobacteria, although it is a common activity observed among this genus ${ }^{(28)}$.

We previously demonstrated that an increase in $\alpha-1,2$ branching of dextrans did not lead to higher selectivity for

Table 4. SCFA and lactic acid concentrations (mM) in pH-controlled batch cultures at $0,10,24$ and $36 \mathrm{~h}$ inoculated with the lean and obese faecal microbiota

(Mean values and standard deviations, $n 4$ )

\begin{tabular}{|c|c|c|c|c|c|c|c|c|c|}
\hline \multirow[b]{3}{*}{ Organic acid } & \multirow[b]{3}{*}{ Time $(\mathrm{h})$} & \multicolumn{4}{|c|}{ Lean faecal fermentation } & \multicolumn{4}{|c|}{ Obese faecal fermentation } \\
\hline & & \multicolumn{2}{|c|}{$\begin{array}{c}\alpha \text {-Gluco- } \\
\text { oligosaccharides }\end{array}$} & \multicolumn{2}{|c|}{ Inulin } & \multicolumn{2}{|c|}{$\begin{array}{c}\alpha \text {-Gluco- } \\
\text { oligosaccharides }\end{array}$} & \multicolumn{2}{|c|}{ Inulin } \\
\hline & & Mean & SD & Mean & SD & Mean & SD & Mean & SD \\
\hline \multirow[t]{4}{*}{ Lactate } & 0 & 0.00 & 0.00 & 0.00 & 0.00 & 0.00 & 0.00 & 0.00 & 0.00 \\
\hline & 10 & $5 \cdot 39^{*}$ & 4.33 & $5 \cdot 16$ & $5 \cdot 12$ & 3.00 & 3.93 & $3 \cdot 10^{\star \star}$ & 2.55 \\
\hline & 24 & 0.00 & 0.00 & 1.24 & 2.47 & 0.00 & 0.00 & 0.00 & 0.00 \\
\hline & 36 & 0.08 & 0.17 & 0.40 & 0.80 & 0.00 & 0.00 & 0.00 & 0.00 \\
\hline \multirow[t]{4}{*}{ Acetate } & 0 & 0.00 & 0.00 & 0.00 & 0.00 & 0.00 & 0.00 & 0.00 & 0.00 \\
\hline & 10 & $26 \cdot 20^{*}$ & $12 \cdot 15$ & $25 \cdot 27^{\star \star}$ & 8.97 & $30 \cdot 96^{\star \star}$ & 18.45 & $28 \cdot 31^{\star \star}$ & 9.64 \\
\hline & 24 & $43 \cdot 88^{\star \star}$ & 10.52 & $34.59^{\star \star}$ & 3.96 & $39 \cdot 20^{\star *}$ & $16 \cdot 79$ & $28.69^{\star \star}$ & $6 \cdot 15$ \\
\hline & 36 & $48 \cdot 90^{a \star \star}$ & $9 \cdot 21$ & $35 \cdot 43^{\star \star}$ & 3.83 & $41.04^{\star \star}$ & 5.37 & $19 \cdot 69^{\star \star}$ & $10 \cdot 84$ \\
\hline \multirow[t]{4}{*}{ Propionate } & 0 & 0.00 & 0.00 & 0.00 & 0.00 & 0.00 & 0.00 & 0.00 & 0.00 \\
\hline & 10 & $9 \cdot 28$ & 8.81 & $10 \cdot 97$ & $5 \cdot 26$ & $12 \cdot 36^{\star}$ & 5.78 & $10 \cdot 08^{\star \star}$ & 4.51 \\
\hline & 24 & 21.83 & $10 \cdot 20$ & $18 \cdot 76^{*}$ & $7 \cdot 72$ & $22 \cdot 56^{\star \star}$ & 8.92 & $11 \cdot 70^{\star \star}$ & $2 \cdot 82$ \\
\hline & 36 & $24 \cdot 19^{*}$ & 8.50 & $19 \cdot 74^{*}$ & 7.04 & $23 \cdot 50^{\star *}$ & 3.05 & $10 \cdot 90^{\star \star}$ & 1.27 \\
\hline \multirow[t]{4}{*}{ Butyrate } & 0 & 0.00 & 0.00 & 0.00 & 0.00 & 0.00 & 0.00 & 0.00 & 0.00 \\
\hline & 10 & 1.52 & $2 \cdot 18$ & $5 \cdot 33$ & 6.96 & 6.01 & $5 \cdot 64$ & 13.77 & $13 \cdot 18$ \\
\hline & 24 & 2.73 & 3.25 & $8 \cdot 30$ & $5 \cdot 12$ & 7.63 & 5.66 & 11.90 & 8.69 \\
\hline & 36 & $3.90^{a}$ & $2 \cdot 71$ & 8.49 & 4.29 & 8.23 & $4 \cdot 16$ & 11.92 & 5.02 \\
\hline \multirow[t]{4}{*}{ Total organic acids } & 0 & 0.00 & 0.00 & 0.00 & 0.00 & 0.00 & 0.00 & 0.00 & 0.00 \\
\hline & 10 & $37 \cdot 00^{\star \star}$ & 21.01 & $41.57^{\star \star}$ & $16 \cdot 10$ & $49 \cdot 32^{\star}$ & $29 \cdot 75$ & $52 \cdot 16^{\star \star}$ & 26.74 \\
\hline & 24 & $68.44^{\star *}$ & 16.94 & $61.65^{\star \star}$ & 3.92 & $69 \cdot 40^{\text {** }}$ & $31 \cdot 10$ & $52 \cdot 29^{\star \star}$ & $15 \cdot 23$ \\
\hline & 36 & $77 \cdot 00^{a * *}$ & $7 \cdot 64$ & $63 \cdot 66^{\star *}$ & 2.03 & $72 \cdot 76^{a \star \star}$ & 11.86 & $42 \cdot 5^{\star \star}$ & 13.96 \\
\hline \multirow[t]{3}{*}{ Acetate:propionate } & 10 & 6.52 & 6.55 & $2 \cdot 65^{\star}$ & $1 \cdot 11$ & $2 \cdot 42^{b \star *}$ & 0.33 & $3 \cdot 01^{\star *}$ & 0.97 \\
\hline & 24 & $2 \cdot 32$ & 0.94 & $2 \cdot 16$ & 1.01 & $1 \cdot 72^{\star *}$ & 0.08 & $2 \cdot 47^{\star \star}$ & 0.17 \\
\hline & 36 & $2 \cdot 24$ & 0.84 & $2 \cdot 13$ & $1 \cdot 21$ & $1 \cdot 75^{\star \star}$ & 0.00 & $1.90^{\star \star}$ & 1.09 \\
\hline
\end{tabular}

Mean value was significantly different from that at $0 \mathrm{~h}:{ }^{*} P<0.05,{ }^{\star \star} P<0.01$.

${ }^{\mathrm{a}, \mathrm{b}}$ Mean values with unlike superscript letters were significantly higher/lower in comparison with inulin and the lean human faecal fermentation values of the same sampling hour $(P<0.05)$. 


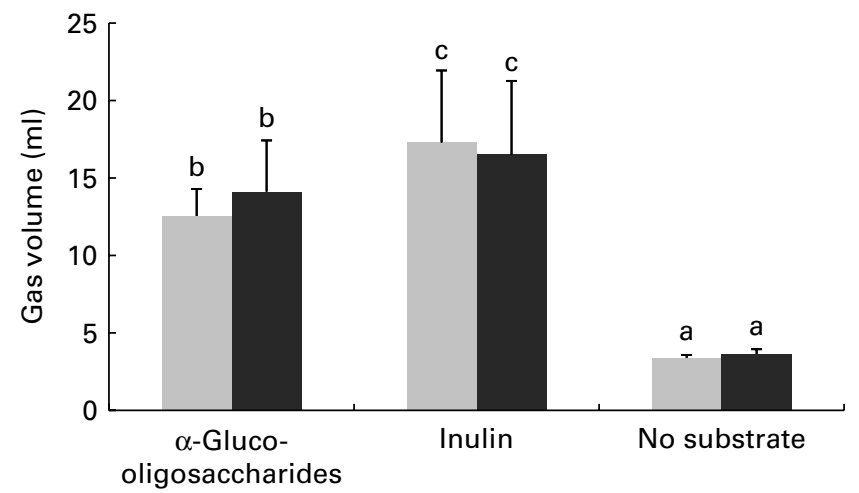

Fig. 2. Total gas production (ml) from $36 \mathrm{~h}$ non-pH-controlled batch culture fermentation inoculated with lean ( $($ ) and obese ( $\square$ ) faecal microbiota $(n 4)$. Values are means, with standard deviations represented by vertical bars. ${ }_{a, b, c}$ Mean values with unlike letters were significantly different among the treatments $(P<0.05)$, with 'a' being the least amount of total gas and ' $c$ ' being the highest amount of total gas.

bifidobacteria. However, branching may decrease the gastrointestinal digestibility of the $1 \mathrm{kDa}$ dextrans as assessed by the higher total dietary fibre content of branched $1 \mathrm{kDa}$ dextrans than linear $1 \mathrm{kDa}$ dextrans ${ }^{(29)}$. A study has found that $\alpha-1,2-$ and $\alpha-1,6-$ linked disaccharides were selective for Bifidobacterium spp. using in vitro faecal cultures ${ }^{(30)}$. These observations are consistent with $\alpha$-gluco-oligosaccharides used in the present study, which consist of a linear $\alpha-1,6$ glucan backbone with $\alpha-1,2$ and $\alpha-1,3$ branching ${ }^{(14)}$.

An in vivo animal study has demonstrated that glucooligosaccharides fed to gnotobiotic rats (inoculated with human faecal microbiota) did not influence major bacterial populations (including bifidobacteria) as opposed to rats fed fructo-oligosaccharides ${ }^{(31)}$. However, this study used culture-based techniques to enumerate bacterial populations disregarding the non-cultivable species. Nevertheless, glucooligosaccharides increased $\beta$-galactosidase and $\alpha$-glucosidase activities and decreased $\beta$-glucuronidase, which could be considered beneficial for the host. $\beta$-Glucuronidase is involved in the generation of toxic and carcinogenic metabolites ${ }^{(32)}$, whereas $\beta$-galactosidase and $\alpha$-glucosidase activities can

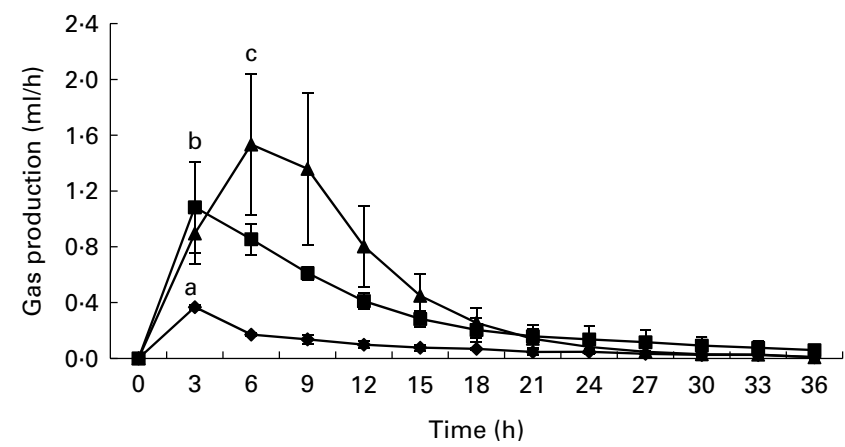

Fig. 3. Gas production pattern expressed in $\mathrm{ml} / \mathrm{h}$ from non-pH-controlled batch culture $(n 4)$ inoculated with lean faecal microbiota. Values are means, with standard deviations represented by vertical bars. ${ }^{a, b, c}$ Mean values with unlike letters were significantly different among the treatments $(P<0.05)$, with 'a' being the slowest gas rate and ' $C$ ' being the fastest gas rate. $\mathbf{\Lambda}, \alpha$-Gluco-oligosaccharides; $\mathbf{\square}$, inulin; $\bullet$, no substrate.

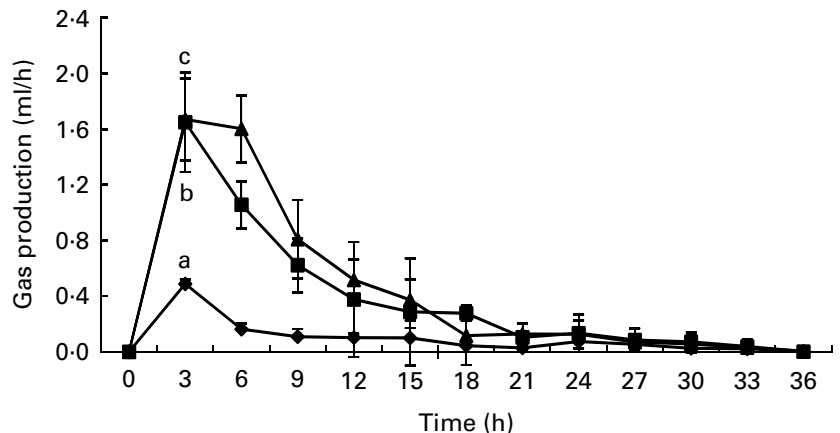

Fig. 4. Gas production pattern expressed in $\mathrm{ml} / \mathrm{h}$ from non-pH-controlled batch culture $(n 4)$ inoculated with obese faecal microbiota. Values are means, with standard deviations represented by vertical bars. ${ }^{a, b, c}$ Mean values with unlike letters were significantly different among the treatments $(P<0.05)$, with 'a' being the slowest gas rate and ' $c$ ' being the fastest gas rate. $\mathbf{\Lambda}, \alpha$-Gluco-oligosaccharides; $\mathbf{\square}$, inulin; $\bullet$ no substrate.

improve carbohydrate fermentation to SCFA ${ }^{(33)}$. A study has shown that $\alpha$-glucosidase from Bifidobacterium breve UCC2003 belongs to a subgroup of the glycosyl hydrolase family 13 , the $\alpha-1$,6-glucosidases (EC 3.2.1.10), which exhibits hydrolytic activity towards $\alpha-1,6$-linked carbohydrates such as panose, isomaltose and isomaltotriose ${ }^{(34)}$. It has also been demonstrated, in non-pH-controlled fermentations, that $\alpha-1,2$ - and $\alpha$-1,6-linked disaccharides were selective for Bifidobacterium spp. ${ }^{(35)}$. The decrease in Faecalibacterium prausnitzii was seen in all fermentations using faecal inocula from lean and obese donors. Another study has demonstrated that a clinical improvement of Crohn's disease was correlated with a significant decrease in $F$. prausnitzii ${ }^{(36)}$.

A preliminary human study has suggested differences between lean and obese human gut microbiota based on sequencing $16 \mathrm{~S}$ ribosomal RNA genes from stool samples ${ }^{(9)}$. However, through the present findings, we did not see any significant difference in the major colonic bacterial groups (except for Lab158) between lean and obese, either on the baseline or subsequent fermentation. In addition, the fermentation of $\alpha$-gluco-oligosaccharides significantly increased Bif164 and Bac303, and decreased Fpra655 in the obese faecal fermentation. This was similar to the lean faecal fermentation, which may suggest that the changes appear to be mainly in response to the substrates. Obesity is thought to be associated with low-grade systemic inflammation ${ }^{(37-41)}$. High numbers of bifidobacteria may decrease endotoxaemia and pro-inflammatory cytokines, further improving glucose tolerance and glucose-induced insulin secretion ${ }^{(42)}$.

Some studies have observed altered proportions of Firmicutes and Bacteroidetes in obese compared with lean mice $e^{(6,7,43)}$. It has also been reported that Firmicutes concentrations were higher in the faeces of obese than lean human subjects $^{(7,44)}$. However, we observed here that the number of Bacteroidetes, Firmicutes and Actinobacteria in baseline faecal samples from obese donors was similar to those from lean donors. Nevertheless, it has to be noted that the present study only involved four donors that could possibly limit the statistical significance of this particular observation. 
Fermentation of $\alpha$-gluco-oligosaccharides induced the production of lactate early in the fermentation, which later declined. This is likely to be due to lactate conversion into SCFA by cross-feeding of other bacteria. The significantly higher concentration of acetate observed on $\alpha$-gluco-oligosaccharides compared with inulin at $36 \mathrm{~h}$ is probably due to a higher population of Bifidobacterium ${ }^{(45)}$. There was also an increase in propionate concentration on both substrates in accordance with a significant increase in the BacteroidesPrevotella group, as these are known to be propionate producers. It has been postulated that propionate may have anti-obesity properties through the reduction of fatty acid levels in plasma ${ }^{(46)}$. High plasma fatty acids are known to cause inflammation, leading to insulin resistance ${ }^{(47)}$. These beneficial effects are usually linked with a reduction in body weight and have been demonstrated to increase satiety ${ }^{(48)}$. Acetate may act as a precursor for cholesterol synthesis, whereas propionate may inhibit this process. Therefore, a low acetate:propionate ratio may be of interest in regulating serum cholesterol levels ${ }^{(49)}$. In the present in vitro study, the fermentation of $\alpha$-gluco-oligosaccharides produced a significantly lower acetate:propionate ratio in the obese faecal fermentation than in the lean faecal fermentation. Therefore, it is suggested to some extent that this type of $\alpha$-gluco-oligosaccharides may demonstrate an anti-obesity effect through its propionate production especially when used in obese people. However, this has to be demonstrated in vivo.

Known producers of propionate include Bacteroides spp. and Clostridium. An example is Bacteroides fragilis that is prevalent in the human gut microbial community, which produces substantial amounts of propionate from succinate and fumarate $^{(50)}$. Species within the Clostridium bistolyticum group can also produce propionate, for example Clostridium homopropionicum $^{(51,52)}$. Clostridial cluster IX contains known propionate producers ${ }^{(52)}$ and species within it (e.g. Succiniclasticum ruminis and Succinispira mobilis) have been reported to convert succinate into propionate ${ }^{(53,54)}$. Through the present study, we only observed significant increases in Bacteroides-Prevotella populations but not in the Clostridium group, i.e. C. bistolyticum and Clostridium cluster IX. Therefore, we suggest that propionate may have been produced by the Bacteroides-Prevotella group. In addition, a previous study has shown that Bacteroides thetaiotaomicron is highly efficient in utilising $\alpha-1,2$ and $\alpha-1,6$ glycosidic linkages that occur in $\alpha$-gluco-oligosaccharides ${ }^{(55)}$.

There is no significant increase in butyrate in the fermentation of both substrates. This may be due to the decrease in the population of major butyrate producers such as F. prausnitzii, Clostridium coccoides-Eubacterium rectale and Ruminococcus groups. An in vitro study has demonstrated that fermentation of $\alpha$-gluco-oligosaccharides resulted in a lower concentration of butyrate compared with fructooligosaccharides $^{(56)}$, which is in agreement with the present findings. In addition, an in vitro study has shown that $\alpha$-gluco-oligosaccharide fermentation resulted in significantly lower butyrate concentration compared with short-, mediumand long-chain fructo-oligosaccharides ${ }^{(57)}$.
Gas production in the large intestine is part of the normal digestive function caused by fermentation of carbohydrate by the gut microbiota. These gases are inevitable fermentation products but are also the main reported disincentive to consumption of prebiotics. Undesirable symptoms relating to gas production in the gut have been widely reported in human prebiotic feeding studies ${ }^{(58)}$. Gastrointestinal discomfort usually occurs with high carbohydrate intakes (more than $20 \mathrm{~g} / \mathrm{d})^{(59)}$. Although it is known that prebiotic target bacteria, i.e. bifidobacteria, do not produce gas, they do produce lactate which can be utilised by gas-producing bacteria such as Clostridium spp., sulphate-reducing bacteria and Bacteroides $^{(60,61)}$. Clostridial clusters IV and XIVa, which are also butyrate producers, have been shown to produce gases, mainly $\mathrm{CO}_{2}$ and $\mathrm{H}_{2}{ }^{(62,63)}$. Fermentation of $\alpha$-glucooligosaccharides resulted in lower quantities of gas, and this was produced more gradually than the fermentation of inulin with both lean and obese faecal slurries. This is in accordance with a previous study which demonstrated that fermentation of gluco-oligosaccharides produced significantly lower amounts of total gas than fructo-oligosaccharides ${ }^{(31)}$.

The in vitro study described here suggested that $\alpha$-glucooligosaccharides (BioEcolians; Solabia) have bifidogenic activity. This, in combination with the fact that glycosidic linkages present results in a very high resistance to hydrolysis by digestive enzymes in both humans and animals ${ }^{(64)}$, makes this type of $\alpha$-glucan an interesting candidate prebiotic and is worthy of further in vivo evaluation. Also, we suggested that the substrate (or diet) but probably not the individual's obese condition can influence the microbiota composition. However, further in vivo work is needed to ultimately confirm this.

\section{Acknowledgements}

The present study was carried out with the financial support from the Department of Food and Nutritional Sciences, University of Reading. The Sarawak Foundation and Universiti Putra Malaysia of the Malaysian government funded a scholarship for S. R. S. The authors' responsibilities were as follows: S. R. S. carried out the study, collected and interpreted the data and wrote the manuscript; S. K. and R. A. R. designed the study, interpreted the data and edited the manuscript; G. R. G. designed the study and edited the manuscript. All authors read and approved the findings of the study. None of the authors had any conflict of interest.

\section{References}

1. Gibson GR, Scott KP, Rastall RA, et al. (2010) Dietary prebiotics: current status and new definition. Food Sci Technol Bull: Funct Foods 7, 1-19.

2. Gibson GR \& Fuller R (2000) Aspects of in vitro and in vivo research approaches directed toward identifying probiotics and prebiotics for human use. J Nutr 130, 391.

3. Chung $\mathrm{CH} \&$ Day DF (2002) Glucooligosaccharides from Leuconostoc mesenteroides B-742 (ATCC 13146): a potential prebiotic. J Indus Microbiol Biotechnol 29, 196-199. 
4. Gibson GR (2004) Fibre and effects on probiotics (the prebiotic concept). Clin Nutr Suppl 1, 25-31.

5. Eckburg PB, Bik EM, Bernstein CN, et al. (2005) Diversity of the human intestinal microbial flora. Science $\mathbf{3 0 8}$, $1635-1638$.

6. Ley RE, Bäckhed F, Turnbaugh P, et al. (2005) Obesity alters gut microbial ecology. Proc Natl Acad Sci U S A $\mathbf{1 0 2}$, 11070-11075.

7. Turnbaugh PJ, Ley RE, Mahowald MA, et al. (2006) An obesity-associated gut microbiome with increased capacity for energy harvest. Nature 444, 1027-1131.

8. Bäckhed F, Manchester JK, Semenkovich CF, et al. (2007) Mechanisms underlying the resistance to diet-induced obesity in germ-free mice. Proc Natl Acad Sci U S A 104, 979-984.

9. Ley RE, Turnbaugh PJ, Klein S, et al. (2006) Microbial ecology: human gut microbes associated with obesity. Nature 444, 1022-1023.

10. Collado MC, Isolauri E, Laitinen K, et al. (2008) Distinct composition of gut microbiota during pregnancy in overweight and normal-weight women. Am J Clin Nutr 88, 894-899.

11. Duncan SH, Lobley GE, Holtrop G, et al. (2008) Human colonic microbiota associated with diet, obesity and weight loss. Int J Obes 32, 1720-1724.

12. Hildebrandt MA, Hoffmann C, Sherrill-Mix SA, et al. (2009) High-fat diet determines the composition of the murine gut microbiome independently of obesity. Gastroenterology 137, 1716-24e2.

13. Murphy EF, Cotter PD, Healy S, et al. (2010) Composition and energy harvesting capacity of the gut microbiota: relationship to diet, obesity and time in mouse models. Gut 59, 1635-1642.

14. Solabia, Bioecolians (2008) http://www.solabia.com/ solabia/solabianutrition.nsf/VS_OPM/37F9DE18A3D1085EC12574EF003066A4? OpenDocument (cited 31 January 2011).

15. Jeanes A, Haynes WC, Wilham CA, et al. (1954) Characterization and classification of dextrans from ninety-six strains of bacteria. J Am Chem Soc 76, 5041-5052.

16. Franks AH, Harmsen HJM, Raangs GC, et al. (1998) Variations of bacterial populations in human feces measured by fluorescent in situ hybridization with group-specific $16 \mathrm{~s}$ rRNA-targeted oligonucleotide probes. Appl Environ Microbiol 64, 3336-3345.

17. Harmsen HJM, Elfferich P, Schut F, et al. (1999) A 16s rRNAtargeted probe for detection of lactobacilli and enterococci in faecal samples by fluorescent in situ hybridization. Microb Ecol Health Dis 11, 3-12.

18. Walker AW, Duncan SH, McWilliam Leitch EC, et al. (2005) $\mathrm{pH}$ and peptide supply can radically alter bacterial populations and short-chain fatty acid ratios within microbial communities from the human colon. Appl Environ Microbiol 71, 3692-3700.

19. Hold GL, Schwiertz A, Aminov RI, et al. (2003) Oligonucleotide probes that detect quantitatively significant groups of butyrate-producing bacteria in human feces. Appl Environ Microbiol 69, 4320-4324.

20. Harmsen HJM, Raangs GC, He T, et al. (2002) Extensive set of $16 \mathrm{~s}$ rRNA-based probes for detection of bacteria in human feces. Appl Environ Microbiol 68, 2982-2990.

21. Manz W, Amann R, Ludwig W, et al. (1996) Application of a suite of 16s rRNA-specific oligonucleotide probes designed to investigate bacteria of the phylum cytophaga-flavobacter-bacteroides in the natural environment. Microbiology 142, 1097-1106.

22. Langendijk P, Schut F, Jansen G, et al. (1995) Quantitative fluorescence in situ hybridization of Bifidobacterium spp. with genus-specific 16s rRNA-targeted probes and its application in fecal samples. Appl Environ Microbiol 61, 3069-3075.

23. Harmsen HJM, Wildeboer-Veloo ACM, Grijpstra J, et al. (2000) Development of 16s rRNA-based probes for the Coriobacterium group and the Atopobium cluster and their application for enumeration of Coriobacteriaceae in human feces from volunteers of different age groups. Appl Environ Microbiol 66, 4523-4527.

24. Cote GL (2007) Flavorings and other value-added products from sucrose. In Novel Enzyme Technology for Food Applications, pp. 243-269 [RA Rastall, editor]. Boca Raton, FL: CRC Press.

25. Olano-Martin E, Mountzouris KC, Gibson GR, et al. (2000) In vitro fermentability of dextran, oligodextran and maltodextrin by human gut bacteria. Br J Nutr 83, 247-255.

26. Kaneko T, Kohmoto T, Kikuchi H, et al. (1994) Effects of isomaltooligosaccharides with different degrees of polymerization on human fecal bifidobacteria. Biosci Biotechnol Biochem 58, 2288-2290.

27. van den Broek LAM, Hinz SWA, Beldman G, et al. (2008) Bifidobacterium carbohydrases - their role in breakdown and synthesis of (potential) prebiotics. Mol Nutr Food Res 52, 146-163.

28. Rada V, Vlková E, Nevoral J, et al. (2006) Comparison of bacterial flora and enzymatic activity in faeces of infants and calves. FEMS Microbiol Lett 258, 25-28.

29. Sarbini SR, Kolida S, Naeye $\mathrm{T}$, et al. (2011) In vitro fermentation of linear and alpha-1,2-branched dextrans by the human fecal microbiota. Appl Environ Microbiol 77, $5307-5315$.

30. Sanz ML, Gibson GR \& Rastall RA (2005) Influence of disaccharide structure on prebiotic selectivity in vitro. J Agric Food Chem 53, 5192-5199.

31. Djouzi Z \& Andrieux C (1997) Compared effects of three oligosaccharides on metabolism of intestinal microflora in rats inoculated with human faecal flora. Br J Nutr $\mathbf{7 8}$, 313-324.

32. Rowland IR (1988) Factors affecting metabolic activity of the intestinal microflora. Drug Metab Rev 19, 243-261.

33. Macfarlane GT \& Cummings JH (1991) The colonic flora, fermentation and large bowel digestive function. In The Large Intestine: Physiology, Pathophysiology and Disease, pp. 51-92 [SF Phillips, JH Pemberton and RG Shorter, editors]. New York: Raven Press.

34. Pokusaeva K, O'Connell-Motherway M, Zomer A, et al. (2009) Characterization of two novel $\alpha$-glucosidases from Bifidobacterium breve UCC2003. Appl Environ Microbiol 75, 1135-1143.

35. Sanz ML, Côté GL, Gibson GR, et al. (2006) Influence of glycosidic linkages and molecular weight on the fermentation of maltose-based oligosaccharides by human gut bacteria. J Agric Food Chem 54, 9779-9784.

36. Jia W, Whitehead RN, Griffiths L, et al. (2010) Is the abundance of Faecalibacterium prausnitzii relevant to Crohn's disease? FEMS Microbiol Lett 310, 138-144.

37. Bastard J-P, Maachi M, Lagathu C, et al. (2006) Recent advances in the relationship between obesity, inflammation, and insulin resistance. Eur Cytokine Netw 17, 4-12.

38. Hotamisligil GS (2006) Inflammation and metabolic disorders. Nature 444, 860-867.

39. Sbarbati A, Osculati F, Silvagni D, et al. (2006) Obesity and inflammation: evidence for an elementary lesion. Pediatrics 117, 220-223.

40. Scanlan PD, Shanahan F, O'Mahony C, et al. (2006) Cultureindependent analyses of temporal variation of the dominant 
fecal microbiota and targeted bacterial subgroups in Crohn's disease. J Clin Microbiol 44, 3980-3988.

41. Fogarty AW, Glancy C, Jones S, et al. (2008) A prospective study of weight change and systemic inflammation over 9 y. Am J Clin Nutr 87, 30-35.

42. Cani PD, Neyrinck AM, Fava F, et al. (2007) Selective increases of bifidobacteria in gut microflora improve highfat-diet-induced diabetes in mice through a mechanism associated with endotoxaemia. Diabetologia 50, 2374-2383.

43. Bäckhed F, Ding H, Wang T, et al. (2004) The gut microbiota as an environmental factor that regulates fat storage. Proc Natl Acad Sci U S A 101, 15718-15723.

44. Turnbaugh PJ, Hamady M, Yatsunenko T, et al. (2009) A core gut microbiome in obese and lean twins. Nature 457, 480-484.

45. Falony G, Lazidou K, Verschaeren A, et al. (2009) In vitro kinetic analysis of fermentation of prebiotic inulin-type fructans by Bifidobacterium species reveals four different phenotypes. Appl Environ Microbiol 75, 454-461.

46. Al-Lahham SaH, Peppelenbosch MP, Roelofsen $\mathrm{H}$, et al. (2010) Biological effects of propionic acid in humans; metabolism, potential applications and underlying mechanisms. Biochim Biophys Acta - Mol Cell Biol Lip 1801, 1175-1183.

47. Kennedy A, Martinez K, Chuang C-C, et al. (2009) Saturated fatty acid-mediated inflammation and insulin resistance in adipose tissue: mechanisms of action and implications. J Nutr 139, 1-4.

48. Ruijschop RMAJ, Boelrijk AEM \& te Giffel MC (2008) Satiety effects of a dairy beverage fermented with propionic acid bacteria. Int Dairy J 18, 945-950.

49. Chen W, Anderson J \& Jennings D (1984) Propionate may mediate the hypo-cholesterolemic effects of certain soluble plant fibers in cholesterol-fed rats. Proc Soc Exp Biol Med 175, 215-218

50. Macy JM, Ljungdahl LG \& Gottschalk G (1978) Pathway of succinate and propionate formation in Bacteroides fragilis. J Bacteriol 134, 84-91.

51. Salminen S, Bouley C, Boutron-Ruault MC, et al. (1998) Functional food science and gastrointestinal physiology and function. Br J Nutr 80, 147-171.

52. Zigová J, SturdIk E, Vandák D, et al. (1999) Butyric acid production by Clostridium butyricum with integrated extraction and pertraction. Proc Biochem 34, 835-843.

53. Janssen PH \& O'Farrell KA (1999) Succinispira mobilis gen Nov., sp. Nov., a succinate-decarboxylating anaerobic bacterium. Int J Syst Evol Microbiol 49, 1009-1013.
54. Van Gylswyk NO (1995) Succiniclasticum ruminis gen Nov., sp. Nov., a ruminal bacterium converting succinate to propionate as the sole energy-yielding mechanism. Int J Syst Bacteriol 45, 297-300.

55. Djouzi Z, Andrieux C, Pelenc V, et al. (1995) Degradation and fermentation of $\alpha$-gluco-oligosaccharides by bacterial strains from human colon: in vitro and in vivo studies in gnotobiotic rats. J Appl Microbiol 79, 117-127.

56. Flickinger EA, Wolf BW, Garleb KA, et al. (2000) Glucose-based oligosaccharides exhibit different in vitro fermentation patterns and affect in vivo apparent nutrient digestibility and microbial populations in dogs. $J$ Nutr 130, 1267-1273.

57. Smiricky-Tjardes MR, Flickinger EA, Grieshop CM, et al (2003) In vitro fermentation characteristics of selected oligosaccharides by swine fecal microflora. J Anim Sci 81, 2505-2514.

58. Hartemink R \& Rombouts FM (1997) Gas formation from oligosaccharides by the intestinal microflora. In Nondigestible Oligosaccharides: Healthy Food for the Colon? Proceedings of the International Symposium, pp. 57-66 [R Hartemink, editor]. Wageningen: Wageningen Graduate School VLAG.

59. Kolida S \& Gibson GR (2007) Prebiotic capacity of inulintype fructans. J Nutr 137, 2503S-2506S.

60. Bernalier A, Dore J \& Durand M (1999) Biochemistry of fermentation. In Colonic Microbiota, Nutrition and Health, pp. 37-53 [GR Gibson and MB Roberfroid, editors]. Dordrecht: Kluwer Academic Publishers.

61. Falony G, Calmeyn T, Leroy F, et al. (2009) Coculture fermentations of Bifidobacterium species and Bacteroides thetaiotaomicron reveal a mechanistic insight into the prebiotic effect of inulin-type fructans. Appl Environ Microbiol 75, 2312-2319.

62. Duncan SH, Louis P \& Flint HJ (2004) Lactate-utilizing bacteria, isolated from human feces that produce butyrate as a major fermentation product. Appl Environ Microbiol $\mathbf{7 0}$ 5810-5817.

63. Duncan SH, Hold GL, Harmsen H, et al. (2002) Growth requirements and fermentation products of Fusobacterium prausnitzii, and a proposal to reclassify it as Faecalibacterium prausnitzii gen. Nov., comb. Nov. Int J Syst Evol Microbiol 52, 2141-2146.

64. Valette P, Pelenc V, Djouzi Z, et al. (1993) Bioavailability of new synthesised glucooligosaccharides in the intestinal tract of gnotobiotic rats. J Sci Food Agric 62, 121-127. 